\title{
Processing of Metallic Thin Films Using Nd:YAG Laser Pulses
}

\author{
Santiago Camacho-López et al.* \\ Departamento de Óptica, Centro de Investigación Científica y de Educación Superior de \\ Ensenada, Carretera Ensenada- Tijuana, Zona Playitas, Ensenada, Baja California \\ México
}

\section{Introduction}

Nd:YAG lasers are possibly the more widely used lasers either for basic research or for industrial and technological applications (Dubey, A. K. \& Yadava, V. 2008). These lasers are also excellent pump sources for laser development, for instance Ti:sapphire ultrashort pulse lasers are based on CW Nd:YAG pumping. In particular, Nd-YAG lasers have been applied to study laser-induced oxidation in metals as titanium and chromium; semiconductors as silicon (Aygun, G. et al., 2006). (Perez del Pino, A. et al., 2004) demonstrated that the rutile phase of $\mathrm{TiO}_{2}$ is obtained by laser oxidation in air of titanium films. Nd:YAG laser pulses have been used to laser-induce a phase transformation from $\mathrm{W}_{3} \mathrm{O}$ thin films to $\mathrm{WO}_{3}$ (Evans R., et al., 2007); laser ablation for micromachining of bulk metals as copper, bronze and aluminum has also been done using Nd:YAG nanosecond pulses (Maisterrena-Epstein R., et al., 2007); laser-induced oxidation and novel LIPSS formation in titanium thin films deposited on silicon substrates was demonstrated by using a single laser beam from a frequency doubled Nd:YAG nanosecond pulsed laser (Camacho-Lopez S., et al., 2008). Some works about pulsed laser oxidation have been reported (Dong, Q. et al., 2002). (Pereira, A. et al. 2004) have investigated the laser treatment in steel irradiating at various wavelengths by using different laser sources. In Table 1, we cited some works on the oxidation induced by pulsed laser irradiation in various metals. Recently, we have published results on fs-laser

\footnotetext{
*Marco A. Camacho-López², Oscar Olea Mejía ${ }^{3}$, Rodger Evans', Gabriel Castillo Vega1,

Miguel A. Camacho-López ${ }^{4}$, Manuel Herrera Zaldivar ${ }^{5}$, Alejandro Esparza García ${ }^{6}$ and José G. Bañuelos Muñetón ${ }^{6}$

${ }^{1}$ Departamento de Óptica, Centro de Investigación Científica y de Educación Superior de Ensenada, Carretera Ensenada- Tijuana, Zona Playitas, Ensenada, Baja California, México

${ }^{2}$ Facultad de Química, Universidad Autónoma del Estado de México, Tollocan s/n, esq. Paseo Colón, Toluca, Estado de México, México

${ }^{3}$ Centro Conjunto de Investigación en Química SustenTable UAEM-UNAM (CCIQS), Facultad de Química, Universidad Autónoma del Estado de México, de la carretera Toluca-Atlacomulco, San Cayetano, México

${ }^{4}$ Facultad de Medicina, Universidad Autónoma del Estado de México, Paseo Tollocan s/n, esq. Jesús Carranza, Toluca, Estado de México, México

${ }^{5}$ Centro de Nanociencias y Nanotecnología, Universidad Nacional Autónoma de México, Carretera TijuanaEnsenada, Ensenada, Baja California, México

${ }^{6}$ Centro de Ciencias Aplicadas y Desarrollo Tecnológico, UNAM, Apdo. Postal 70-186, México, DF, México
} 
oxidation in molybdenum thin films (Cano-Lara, M. et al., 2011). (Herman et al., 2006) have studied ablation of molybdenum thin films with short and ultrashort laser pulses. This work is the first study with Nd:YAG to investigate pulsed laser oxidation in molybdenum thin films.

\begin{tabular}{|c|c|c|}
\hline Material & $\begin{array}{l}\text { Research group } \\
\text { Starting material } \\
\text { Laser line } \\
\end{array}$ & \\
\hline Titanium & $\begin{array}{ll}\text { (Pérez del Pino et al. 2002) } & \text { (Lavisse, L. et al. 2002) } \\
\text { Titanium targets } & \text { Titanium targets } \\
\lambda=1064 \mathrm{~nm} & \lambda=1064 \mathrm{~nm}\end{array}$ & $\begin{array}{l}\text { (Camacho-López, S. et al } \\
\text { 2008) } \\
\text { Titanium thin films } \\
\lambda=532 \mathrm{~nm}\end{array}$ \\
\hline Chromium & $\begin{array}{l}\text { (Dong, Q. et al. 2002) } \\
\text { Chromium films } \\
\lambda=1064 \mathrm{~nm}\end{array}$ & \\
\hline Steel & $\begin{array}{l}\text { (Pereira, A. et al. 2004) } \\
\text { Steel target } \\
1064 \mathrm{~nm} \\
532 \mathrm{~nm}\end{array}$ & \\
\hline Molybdenum & $\begin{array}{c}\text { Our work } \\
\text { Molybdenum Thin Films } \\
\lambda=532 \mathrm{~nm}\end{array}$ & \\
\hline
\end{tabular}

Table 1. Some works on Nd-YAG pulsed laser oxidation.

Some advantages of laser-induced metallic oxides are:

1. Oxidation can be performed in air, so that a controlled atmosphere is not necessary.

2. The time that it takes to achieve a given stoichiometry and crystalline phase is very rapid as compared to conventional thermal treatment.

3. A high spatial resolution patterning of metallic oxides is only possible by this method. Sizes are determined by the optical diffraction limit, therefore single "pixels" made of metallic oxide in the order of the laser light wavelength are possible.

4. In some cases, the laser-induced oxidation process is accompanied by laser-induced periodic surface structures (LIPSS) formation.

Titanium dioxide is an important material due to its wide range of applications. Titanium dioxide is a biocompatible material; in its thin film form, $\mathrm{TiO}_{2}$ has applications as an antireflective coating, or anticorrosive coating. Additionally, titanium dioxide has applications as gas sensor material, in photocatalysis, among others (Linsebigler A. M. et al., 1995). It is well known that $\mathrm{TiO}_{2}$ exist as a crystalline material in three phases: anatase, rutile and brookite (Beattie, I. R., Gilson, T. R. 1969).

Molybdenum oxides are attractive materials due to its potential technological applications. $\mathrm{MoO}_{3}$ possesses photo-, electro- and gasochromic properties (Livage, J. \& Ganguli, D. 2001). For instance, this material can be used in gas sensors, catalysis, smart windows, lithium microbatteries (Dieterle, M. 2001). $\mathrm{MoO}_{2}$ has potential applications as a cathode material in the area of microbatteries; field emission, and also catalysis (Jun, Z. et al. 2003; Wang F. \& Lu B. 2009; Mikhailova, D. et al. 2011).

The micro-Raman technique is very useful to obtain information about the composition and structure of the material into the laser irradiated zone. Spatially studies can be carried out 
since the laser beam can be Focalized down on the sample to $2 \mu \mathrm{m}$ diameter (Witke, K. et al. 1998). For instance, we have obtained spatially resolved information about what kind of material is formed when a molybdenum thin film was irradiated with fs-laser pulses (CanoLara, M. et al., 2011).

In this chapter we present and discuss a series of experimental results on short (nanoseconds) and ultrashort (picoseconds) pulsed Nd:YAG laser processing of metallic thin films. Our selection of materials consisted of molybdenum (Mo) and titanium (Ti) thin films deposited on glass substrates and silicon wafers by the DC-magnetron sputtering technique. We studied the ablation features on the selected materials; once the ablation threshold fluence was determined, we carried out laser processing experiments setting our delivered fluence to a value well below ablation threshold. Under such a scenario we studied the following phenomena: laser-induced periodic surface structures (LIPSS) formation, and laser-induced oxidation on the metallic films. Our results show that it is possible to laser-induce $\mathrm{MoO}_{2}$ and $\mathrm{TiO}_{2}$ inside the irradiated zone; we also found that for certain laser irradiation conditions it is possible to obtain LIPSS formation driven by the polarization of the recording beam. The characterization of the laser irradiated metallic thin films consisted mainly on Atomic Force Microscopy (AFM), Scanning Electron Microscopy (SEM), and micro-Raman Spectroscopy.

\section{Materials and methods}

\subsection{Deposition of titanium and molybdenum thin films}

Titanium and molybdenum thin films were deposited using disks of titanium and molybdenum (99.9\%, Lesker), respectively. Ar gas was used to sputter the targets by means of the DC-magnetron sputtering technique. Glass slides and silicon wafers were used as substrates. In Table 2, one can see the deposition parameters used to obtain each material.

\begin{tabular}{llll}
\hline Deposition parameters & Titanium/silicon & Titanium/glass & Molybdenum/glass \\
\hline Discharge Power & $30 \mathrm{~W}$ & $100 \mathrm{~W}$ & $150 \mathrm{~W}$ \\
\hline Pressure & $1 \times 10^{-3} \mathrm{mBar}$ & $1.4 \times 10^{-3} \mathrm{mBar}$ & $1.4 \times 10^{-3} \mathrm{mBar}$ \\
\hline Target-substrate separation & $7 \mathrm{~cm}$ & $7 \mathrm{~cm}$ & $7 \mathrm{~cm}$ \\
\hline Deposition time & $40 \mathrm{~min}$ & $16 \mathrm{~min}$ & $10 \mathrm{~min}$ \\
\hline Substrate & Silicon wafer(100) & Glass slide & Glass slide \\
\hline Substrate temperature & room & room & room \\
\hline
\end{tabular}

Table 2. Deposition parameters for titanium and molybdenum thin films.

\subsection{Laser processing of the metal thin films}

The experiments were performed using a typical laser processing set up (see Figure 1) which consist of a computer controlled $\mathrm{x}-\mathrm{y}-\mathrm{z}$ translation stage, where the sample is conveniently hold; the laser beam from either a nanosecond (ns) or a picosecond (ps), frequency doubled, pulsed Nd:YAG laser was used to irradiate the samples at normal incidence; the laser beam can be either focused or non-focused onto the sample. The laser irradiation was carried out at $10 \mathrm{~Hz}$ repetition rate, using a single beam, taking care of using a per pulse laser fluence below the ablation threshold for the selected metallic films.

The delivered fluence is controlled by means of an attenuator made of a half-wave plate and a polarizer. An extra half-wave plate, or a quarter-wave plate, is used to change from linear 
polarization to linear polarization with another orientation, or from linear to circular polarization. The as-deposited metallic thin films were exposed to a series of thousands of pulses.
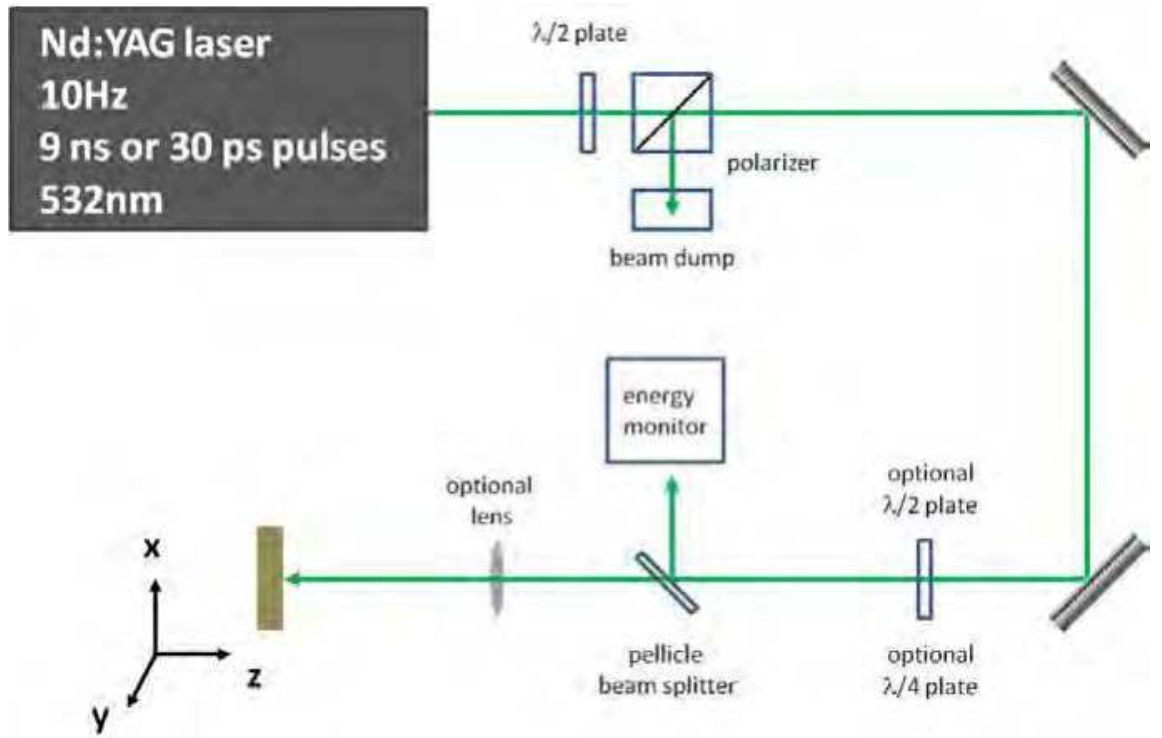

Fig. 1. LIPSS and laser-induced oxidation experimental set up.

\begin{tabular}{llll}
\hline Irradiation parameters & Titanium/silicon & Titanium/glass & Molybdenum/glass \\
\hline Laser Fluence (per pulse) & $0.24 \mathrm{~J} / \mathrm{cm}^{2}$ & $0.08 \mathrm{~J} / \mathrm{cm}^{2}$ & $0.08 \mathrm{~J} / \mathrm{cm}^{2}$ \\
\hline Wavelength & $532 \mathrm{~nm}$ & $532 \mathrm{~nm}$ & $532 \mathrm{~nm}$ \\
\hline Repetition frequency & $10 \mathrm{~Hz}$ & $10 \mathrm{~Hz}$ & $10 \mathrm{~Hz}$ \\
\hline Pulse number & 4000 & 4000 & 6000 \\
& & 8000 & \\
& & 12000 & 12000 \\
& & 18000 \\
\hline Atmosphere & air & air & $10000\left(0.16 \mathrm{~J} / \mathrm{cm}^{2}\right)$ \\
\hline Substrate temperature & room & room & air \\
\hline
\end{tabular}

Table 3. Irradiation parameters for the ns laser exposures

\begin{tabular}{lll}
\hline Irradiation parameters & Titanium/glass & Molybdenum/glass \\
\hline Laser Fluence (per pulse) & $0.24 \mathrm{~J} / \mathrm{cm}^{2}$ & $0.24 \mathrm{~J} / \mathrm{cm}^{2}$ \\
\hline Wavelength & $532 \mathrm{~nm}$ & $532 \mathrm{~nm}$ \\
\hline Repetition frequency & $10 \mathrm{~Hz}$ & $10 \mathrm{~Hz}$ \\
\hline Pulse number & $2000,4000,6000$ & $2000,4000,6000$ \\
& 8000,10000 & 8000,10000 \\
\hline Atmosphere & air & air \\
\hline Substrate temperature & room & room \\
\hline
\end{tabular}

Table 4. Irradiation parameters for the ps laser exposures 
The pair of frequency doubled Nd:YAG lasers: a Continuum, minilite II, 9 ns pulse duration; and a Ekspla, 30 ps pulse duration, were used to irradiate the metallic thin film samples in atmospheric air. The laser irradiation parameters we used in the experiments are presented in Tables 3 and 4.

\subsection{Characterization of the as-deposited Titanium and Molybdenum thin films and the laser exposed sites}

The as-deposited molybdenum and titanium thin films were characterized by X-Ray Diffraction (Bruker D8 Advance with Linxeye detector) with the $\mathrm{Cu} K \alpha$ radiation source $(\lambda=$ $1.5406 \AA$ ) and a Scanning Electron Microscope (SEM). The SEM analysis was performed with a JEOL JSM-6510LV microscope in the high vacuum mode. The samples were characterized without any conductive coating with secondary electrons; the acceleration voltage was $20 \mathrm{kV}$. The AFM analysis was done using a Veeco CP-II in contact mode with a silicon nitride tip. The scanned size is $5 \times 5$ microns. The modified material which turns into metallic oxides during the irradiation process was characterized by microRaman spectroscopy. A micro-Raman system, LabRaman HR-800 of Jobin-Yvon-Horiba, was used to run and capture the micro-Raman spectra. The $632.8 \mathrm{~nm}$ line of a He-Ne laser was utilized to excite the material and the laser power at the sample was $5 \mathrm{~mW}$. An Olympus BX-41 optical microscope was used to focus down the laser beam on the sample and to collect the scattered light. This was done using a 100X microscope objective lens. All the spectra are the result of 10 acquisitions of $60 \mathrm{~s}$.

\section{Experimental results}

\subsection{X-Ray Diffraction of the as deposited thin films}

Figure 2 shows the XRD patterns for the sputtered deposited titanium and molybdenum thin films. The titanium XRD pattern (Figure 2a) contains peaks corresponding to the (002), (101), (102) and (103) reflection planes, that according to the literature correspond to the $\alpha-\mathrm{Ti}$ phase. The diffraction peaks in the case of the molybdenum thin film (Figure $2 b$ ) correspond to the (110) and (220) reflection planes. This indicates that the molybdenum thin films grew preferentially acquiring the cubic phase.

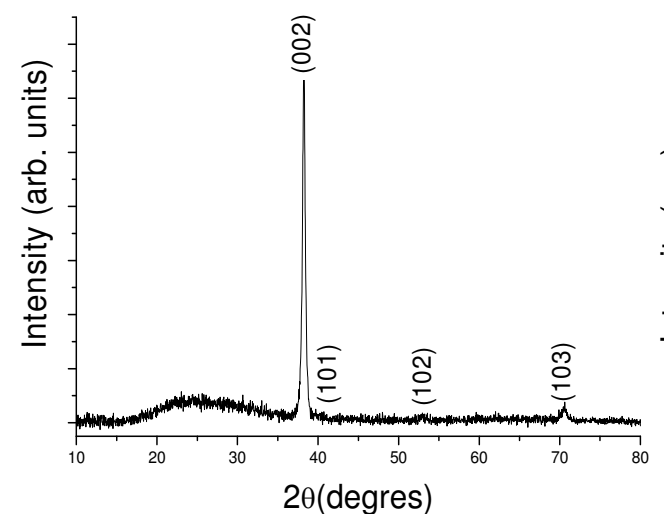

(a)

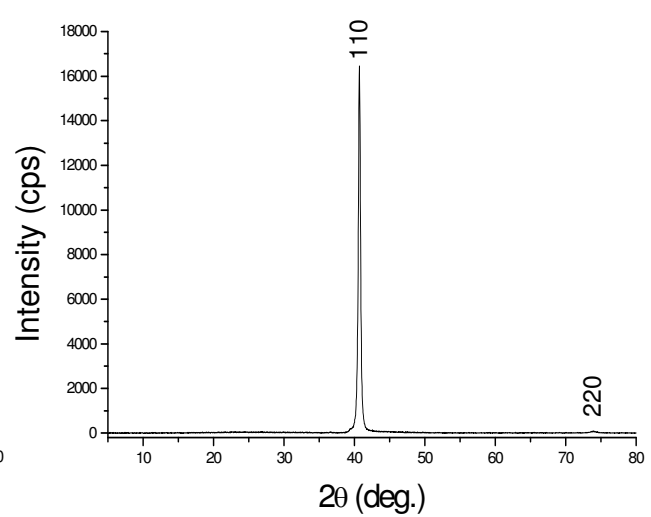

(b)

Fig. 2. XRD patterns of the as deposited thin films: (a) titanium and (b) molybdenum. 


\subsection{LIPSS formation characterized by AFM}

\subsubsection{Titanium / Silicon and ns pulses laser irradiation}

A $320 \mathrm{~nm}$ thick Ti thin film deposited on silicon (100) was irradiated using a frequency doubled Nd:YAG laser, with pulses of 9 ns duration at $10 \mathrm{~Hz}$ repetition rate, and a per pulse laser fluence of $0.24 \mathrm{~J} / \mathrm{cm}^{2}$. The delivered fluence is well below the ablation threshold, which according to (Vorobyev, A. Y. \& C. Guo, C. 2007) is in the order of $0.8 \mathrm{~J} / \mathrm{cm}^{2}$. Figure 3 clearly shows the formation of laser-induced periodic surface structures (LIPSS), such an effect takes place as a result of applying thousands of pulses. In this particular case, we are showing the formation of LIPSS for an exposure of 4000 pulses. Figure 3a, shows an AFM image from a non-irradiated zone in the as-deposited thin film, a homogeneously smooth surface can be identified, it is constituted by a compact layer of nanosized grains. Figures $3 \mathrm{~b}-\mathrm{d}$ show the results of the laser exposures on the Ti film; when either a linear or a circular polarized beam is used the film surface experiences significant changes. In Figures $3 b-c$, a linear polarized beam was used, notice that in those cases grating-like structures are formed, whose orientation follows the laser polarization direction (indicated with a blue arrow and a E which stands for the light electric field); we must observe that the grating-like structures are covered with quasi-periodically distributed craters. If we switch from a given laser linear polarization to the orthogonal linear polarization orientation the grating-like structure follows the polarization orientation. An interesting and expected result is shown in Figure $3 \mathrm{~d}$, where it is noticed that when circular polarization is used there is no LIPSS formation at all, however, a series of craters of a few hundred nanometers diameter are formed. Those craters are of the same nature than the ones formed on the grating-like structures under linear polarization exposures; as discussed in (S. Camacho-Lopez et al., 2008) those craters could be formed due to enhanced field effects, which would produce ablation at specific sites with sizes below the wavelength scale. Notice too that the initial nanosized grains that constitute the thin film seem to preserve well under circularly polarized light exposures.

In Figure 3e, we have a cross profile from one of the grating-like structures that result from the linear polarization exposures. It can be easily seen how the grooves periodicity is in the order of the laser wavelength $(532 \mathrm{~nm})$; this fact is already well known in the LIPSS literature. However, we must note in this case that while in the great majority of the LIPSS reports in metals, the LIPSS formation comes from using laser fluences above the melting and even ablation thresholds (Sipe, J. E. et al., 1983; Young, J. F., et a., 1983); in our case the LIPSS features are not the result of melting or ablation, but the result of laser-induced oxidation of the Ti film. S. Camacho-Lopez et al., reported, back in 2008 for the very first time, LIPSS made of a metallic oxide. An interesting feature is that while in most of the reported work the LIPSS orientation is perpendicular to the laser polarization orientation, in the present case the LIPSS form consistently oriented parallel to the laser beam polarization.

On the optical side effects resulting of the LIPSS formation, we must mention that an angular selective reflectance was obtained when the processed sample is illuminated obliquely under white light and the sample is rotated around the normal to its surface (Camacho-Lopez S., et al., 2008). If the angle of incidence of the white light beam is varied a whole selection of colors is obtained by diffraction off the grating-like structures. 


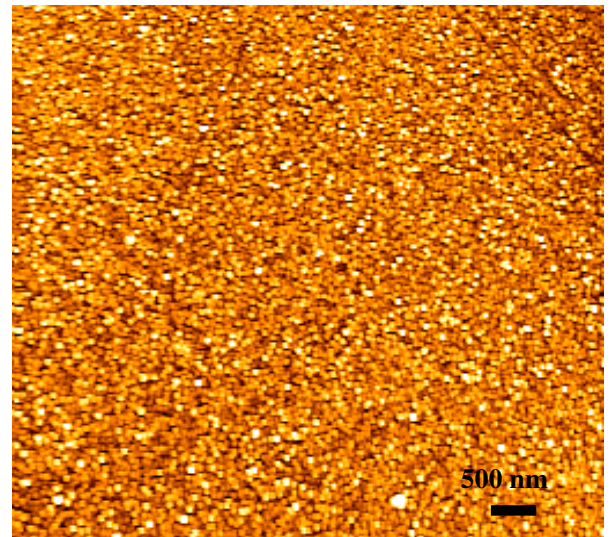

(a)

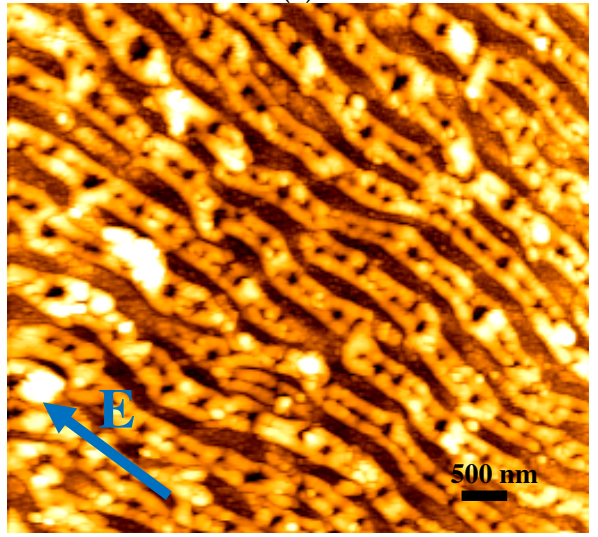

(c)

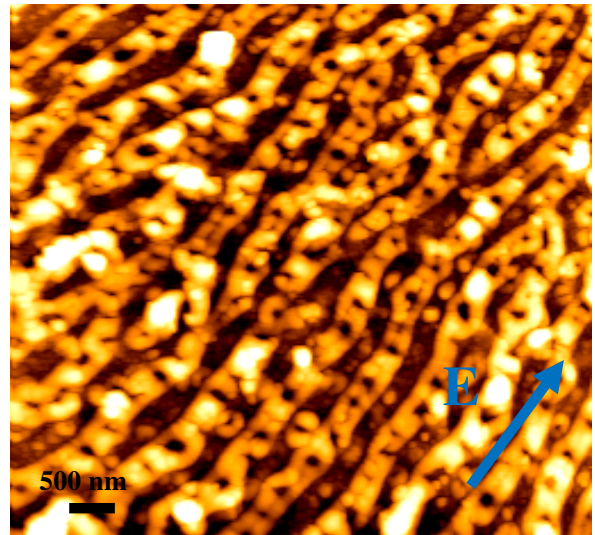

(b)

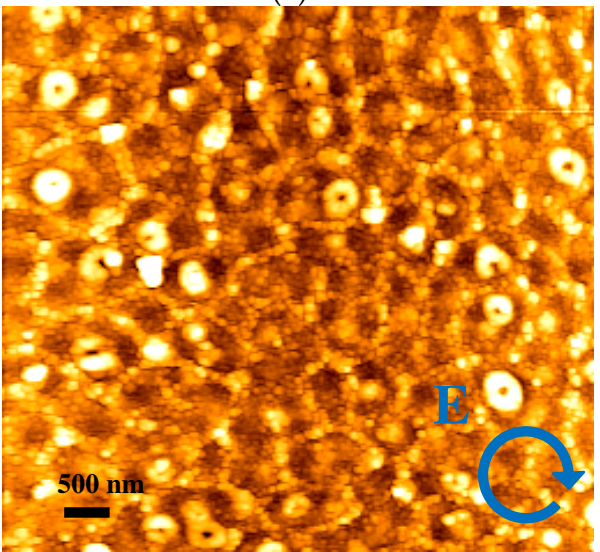

(d)

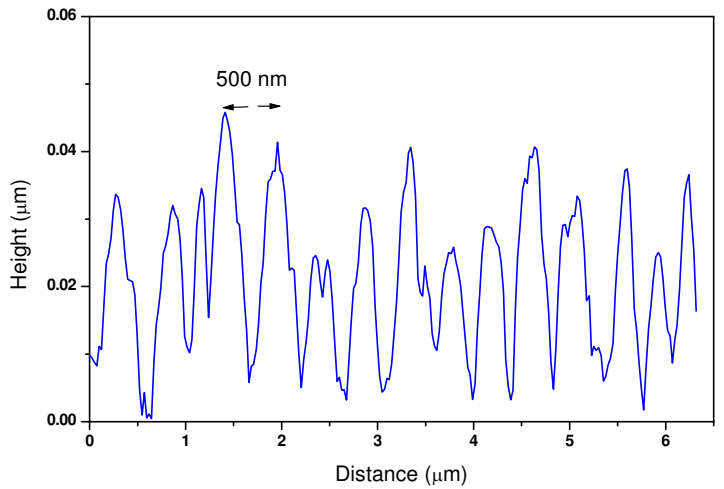

(e)

Fig. 3. AFM micrographs for a) an as deposited titanium film deposited in silicon and b-c) laser exposed spots to linear polarization and d) circular polarization; e) is a cross profile of the grating-like structures formed for linear polarization. 


\subsubsection{Molybdenum / glass and ps pulses laser irradiation}

For the case of molybdenum, a thin film deposited on glass was laser irradiated with a frequency doubled Nd:YAG ps pulsed laser using the parameters already mentioned above (Table 4). LIPSS formation is easily obtained, as it shown in Figure 4, for a number of pulses as low as 2000. The LIPSS formation in this case is oriented perpendicular to the laser beam linear polarization (Figure 4a). Notice that craters as those showed in Figure 3 are not formed in this case. Another characteristic to notice here is the fact that the LIPSS periodicity is in the order of twice the laser wavelength (Figure $4 \mathrm{~b}$ ). It is important to point out that a sort of cone shaped structures can be identified to cover the main LIPSS formation; a 3-D AFM profile of such cone shaped structures is presented in Figure 4c, for the case of a spot that has been irradiated with 2000 ps laser pulses.

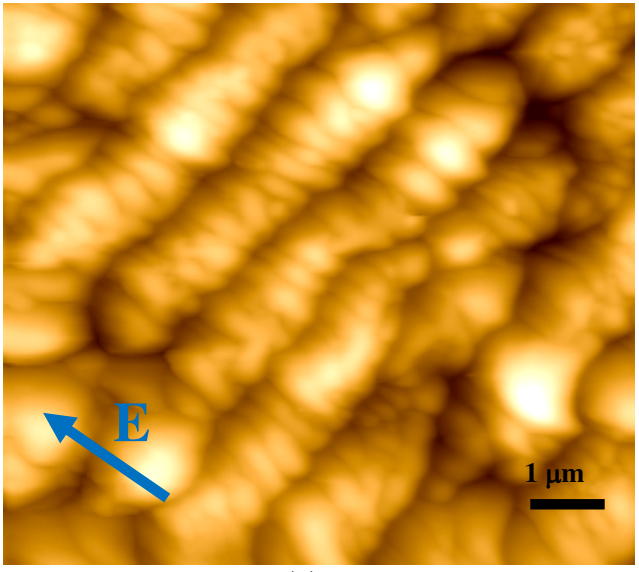

(a)

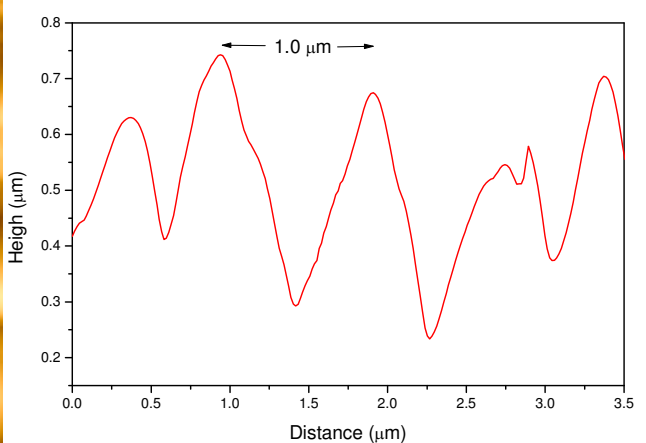

(b)

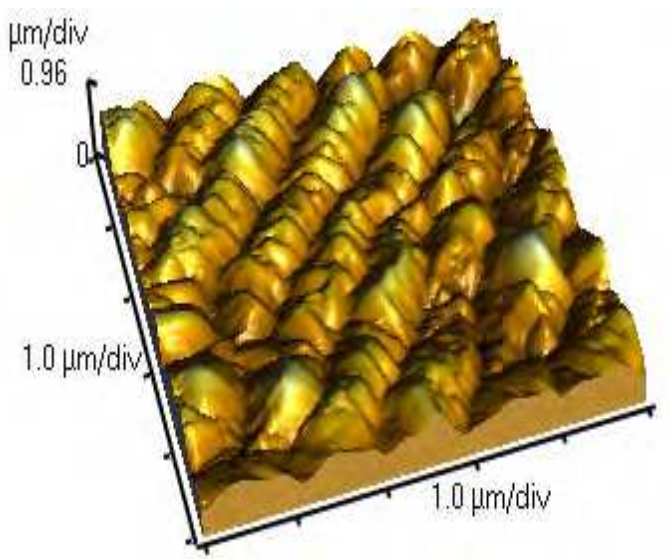

(c)

Fig. 4. AFM micrographs for a molybdenum thin film laser exposed to 2000 ps laser pulses.

a) 2-D image of the LIPSS; b) cross profile that shows the LIPSS periodicity; c) 3-D micrograph of the cone shaped structures that cover the main LIPSS. 


\subsection{LIPSS formation characterized by SEM}

\subsubsection{Titanium / glass for ns and ps pulses laser irradiation}

The as-deposited (on glass substrates) metallic thin films, for both selected metals (Ti and Mo), show smooth and homogeneous surfaces, this is seen for titanium in Figure 5a, and molybdenum in Figure 6a. In the specific case of the as-deposited titanium, the film shows very compact nanosized grain structure; while in the case of the as-deposited molybdenum, a nano-porous structure dominates the film surface texture.

The titanium thin film (500 nm thick) was irradiated using $9 \mathrm{~ns}$ laser pulses (see Table 3 ) and a per pulse fluence of $0.08 \mathrm{~J} / \mathrm{cm}^{2}$, at a repetition rate of $10 \mathrm{~Hz}$; from Figure $5 \mathrm{~b}$ we can observe that after 4000 pulses the surface of the metallic thin film, suffers almost no change in its morphology and texture. A few cracks developed but the nanosized grain layer still dominates the titanium film. We must mention though that no matter the lack of LIPSS formation, there is a definitely laser-induced oxidation effect on the Ti thin film, this is shown in the following section dedicated to micro-Raman characterization.

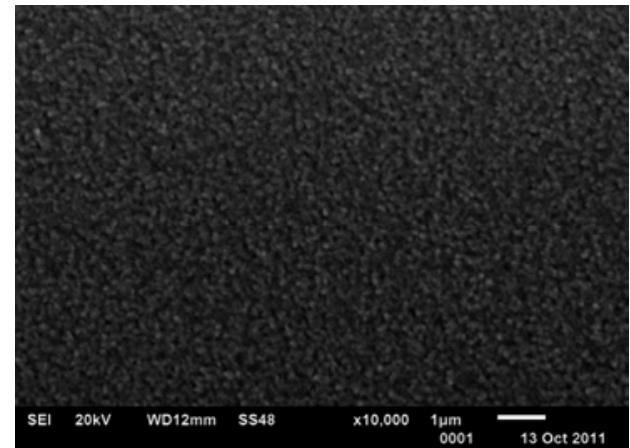

(a)

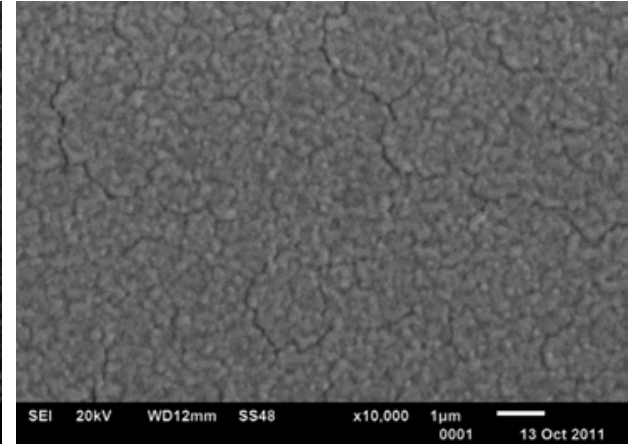

(b)

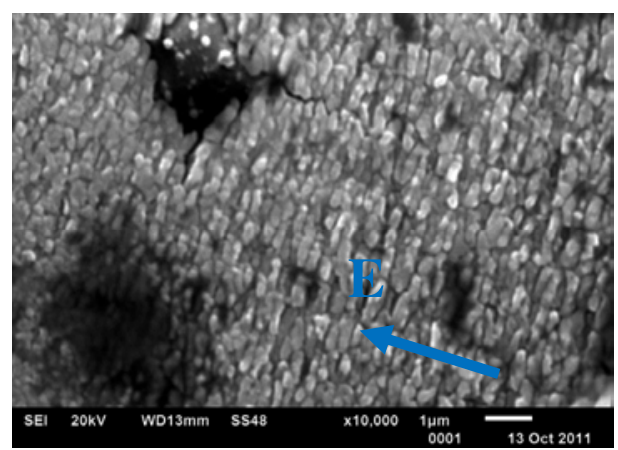

(c)

Fig. 5. SEM titanium: a) as-deposited Ti thin film; laser irradiated with b) 4000 ns pulses, c) 2000 ps pulses.

When the titanium thin film ( $500 \mathrm{~nm}$ thick) was irradiated using a 30 ps pulse duration at 10 $\mathrm{Hz}$ repetition rate and a per pulse delivered fluence of $0.24 \mathrm{~J} / \mathrm{cm}^{2}$, and the number of pulses was set to 2000, the film is significantly modified. Figure $5 \mathrm{c}$ shows a typical SEM micrograph 
of the irradiated spot, where we can see LIPSS formation in a similar manner as we observed in the case of the titanium on silicon substrate irradiated with ns laser pulses. It must be noticed though that the LIPSS features in the ps laser irradiation case present some differences as compared to the ns laser irradiation results; we can see for instance that the oriented structures formed in a denser pattern, notice too that the craters formed in the case of ns laser pulses do not appear in the ps laser pulses case. A very relevant feature, however, is that the orientation of the formed LIPSS on the ps laser pulses case is orthogonal to the laser beam polarization. As expected, the grating-like structures periodicity is in the order of the laser wavelength, which is consistent to the known facts of the LIPSS formation phenomenon. The deep and dark areas in the micrograph most likely correspond to an inhomogeneous intensity distribution across the laser beam and therefore across the laser exposed area. Another feature we must notice is that the grating-like structures in this case are composed by rectangular platelets which actually flake off the sample.

\subsubsection{Molybdenum / glass for ns and ps pulses laser irradiation}

Figure 6 shows the as-deposited on glass substrate molybdenum thin film (Figure 6a); the ns pulses laser irradiated sample (Figure 6b) and the ps pulses laser irradiated sample (Figure 6c-d).

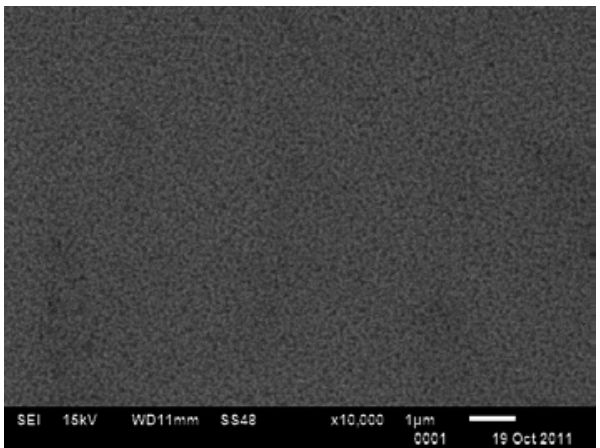

(a)

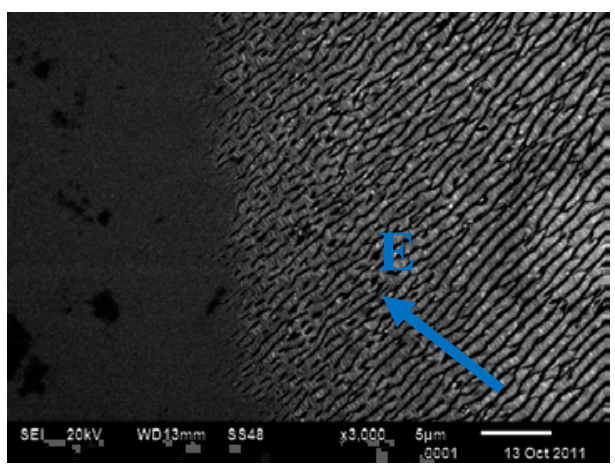

(c)

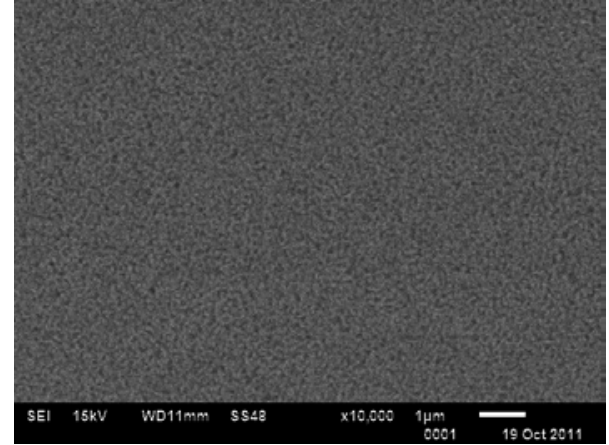

(b)

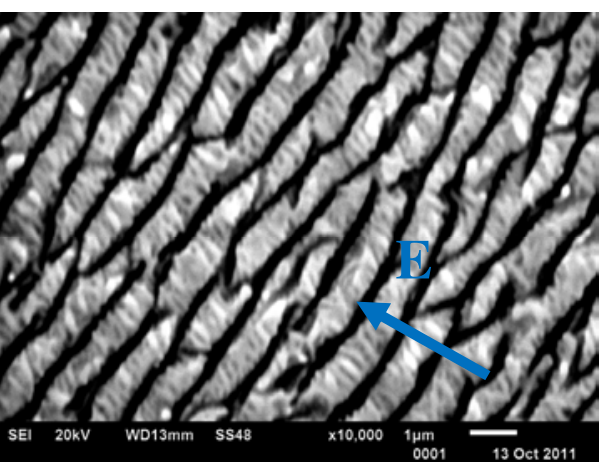

(d)

Fig. 6. SEM molybdenum: a) as-deposited thin film; laser irradiated with b) 18000 ns pulses, c) 2000 ps pulses, notice the sharp border between the laser affected and the non-affected zones, d) LIPSS zoom in. 
As it occurred in the case of titanium, the ns pulses laser irradiation did not affected the molybdenum surface texture at all (Figure 6b) for up to 18000 pulses of a per pulse fluence of $0.08 \mathrm{~J} / \mathrm{cm}^{2}$, however, as it is shown in the following section dedicated to micro-Raman characterization, a laser-induced oxidation effect takes place as a result of the laser exposure.

For the ps pulses laser irradiation of the molybdenum thin film, as previously mentioned in the AFM section, the orientation of the formed LIPSS is perpendicular to the laser beam polarization. An interesting feature to be noted is a tendency to bifurcation across the grooves formed (Figure 6c-d). There are a few reports of LIPSS formed under femtosecond laser irradiation in metals, where the bifurcation effect is presented although it has not been explained yet. Notice too that craters as those showed in Figure 3 are not formed in this case; this is consistent with the results obtained on titanium deposited on glass when irradiated with the ps laser pulses.

\subsection{Pulsed laser-induced oxidation characterized by micro-Raman spectroscopy}

The micro-Raman spectra for the titanium thin film irradiated with ns is showed in Figure 7. Raman spectra are displayed between 200 to $800 \mathrm{~cm}^{-1}$. The spectra $7(\mathrm{a}-\mathrm{c})$ correspond to irradiated zones with 4000, 8000 and 12000 pulses at $0.08 \mathrm{~J} / \mathrm{cm}^{2}$.

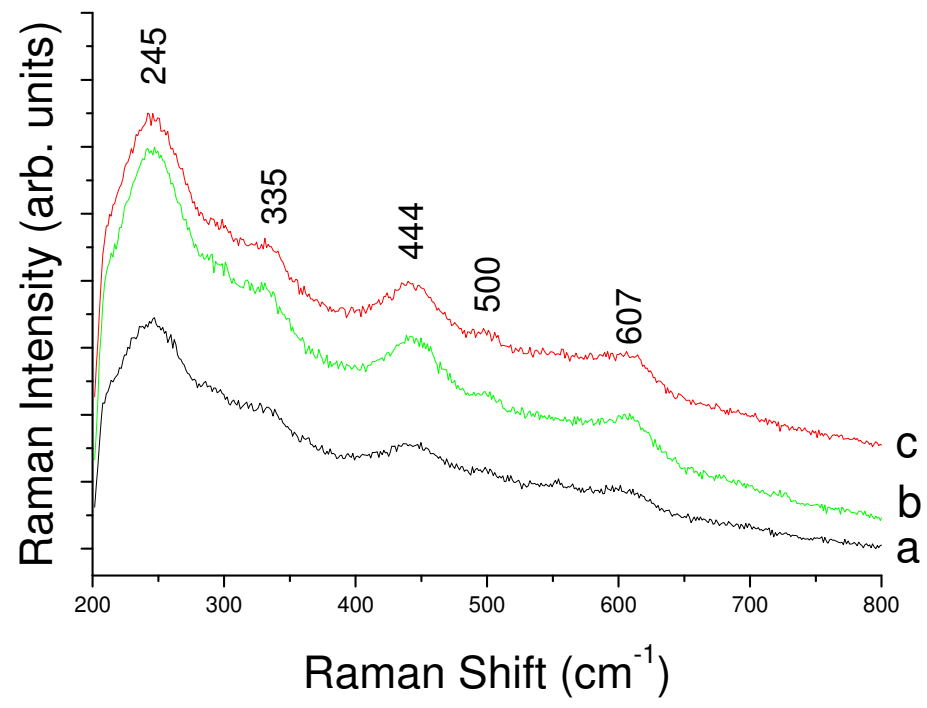

Fig. 7. micro-Raman spectra of a titanium film irradiated at : a) 4000, b) 8000 and c) $12000 \mathrm{~ns}$ pulses.

The micro-Raman spectra for the titanium thin film irradiated with ps are showed in figure 8. Raman spectra are displayed between 200 to $800 \mathrm{~cm}^{-1}$. The spectra 8 (a-d) correspond to irradiated zones with 2000, 4000, 6000 and 8000 pulses at $0.24 \mathrm{~J} / \mathrm{cm}^{2}$. It can be observed the presence of bands mainly at 442 and $610 \mathrm{~cm}^{-1}$.

Figure 9 shows a set of micro-Raman spectra for the molybdenum thin film irradiated with ns laser pulses. The Raman spectra are displayed between 200 to $1000 \mathrm{~cm}^{-1}$. For comparison 
purposes, the micro-Raman spectrum 9(a) of $\mathrm{m}-\mathrm{MoO}_{2}$ powder was included (CamachoLópez M. A. et al., ). The spectra 9(b-d) correspond to irradiated zones with 6000, 12000 and 18000 pulses at $0.08 \mathrm{~J} / \mathrm{cm}^{2}$. The spectrum 9(e) corresponds to an irradiated zone with 10000 pulses at $0.16 \mathrm{~J} / \mathrm{cm}^{2}$. In all cases, micro-Raman spectra are constituted by peaks in the range $200-800 \mathrm{~cm}^{-1}$.

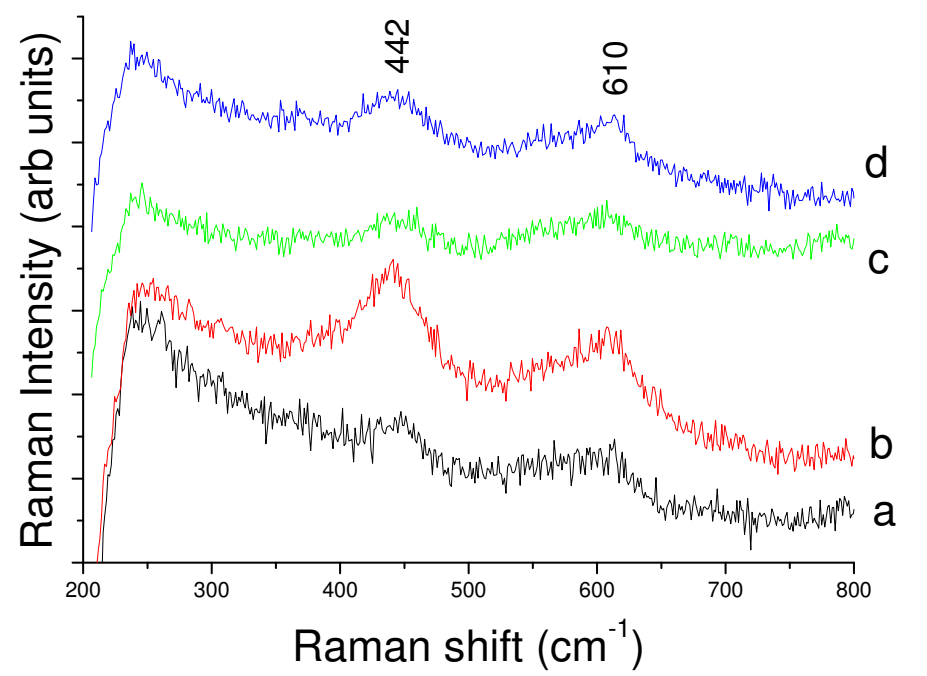

Fig. 8. Raman spectra of the titanium thin film irradiated with ps laser pulses: a) 2000, b) 4000, c) 6000 , d) 8000 pulses

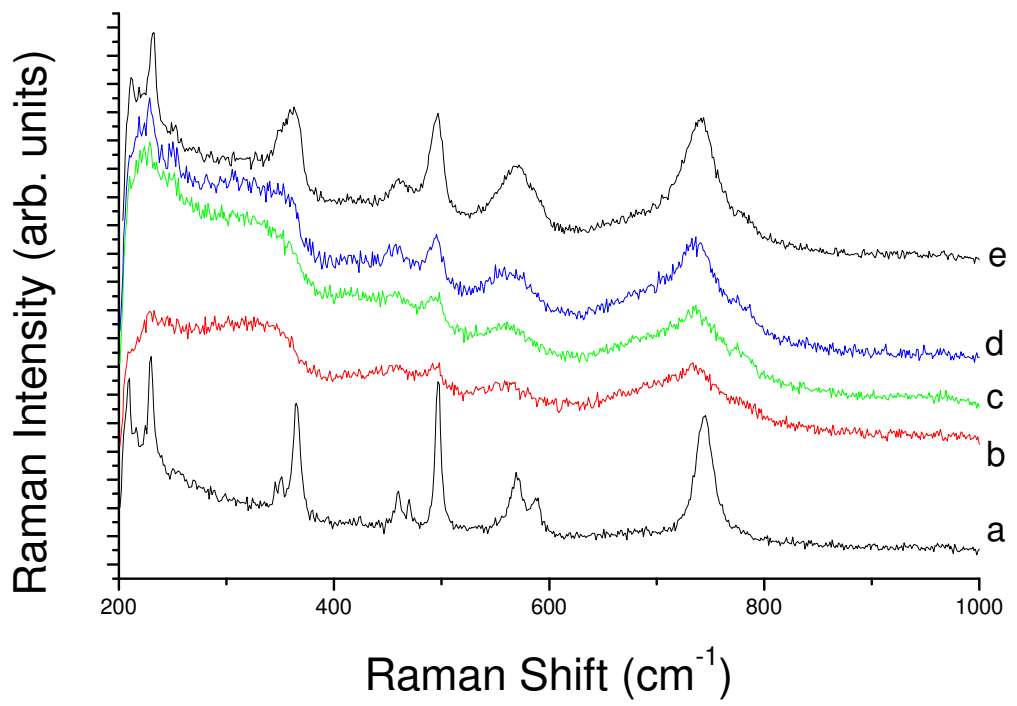

Fig. 9. Micro-Raman spectra of: a) $\mathrm{m}-\mathrm{MoO}_{2}$ powder; molybdenum thin film irradiated with ns pulses b) 6000 , c) 12000 and d) 18000 pulses at $0.08 \mathrm{~J} / \mathrm{cm}^{2}$, e) 10000 pulses at $0.16 \mathrm{~J} / \mathrm{cm}^{2}$. 


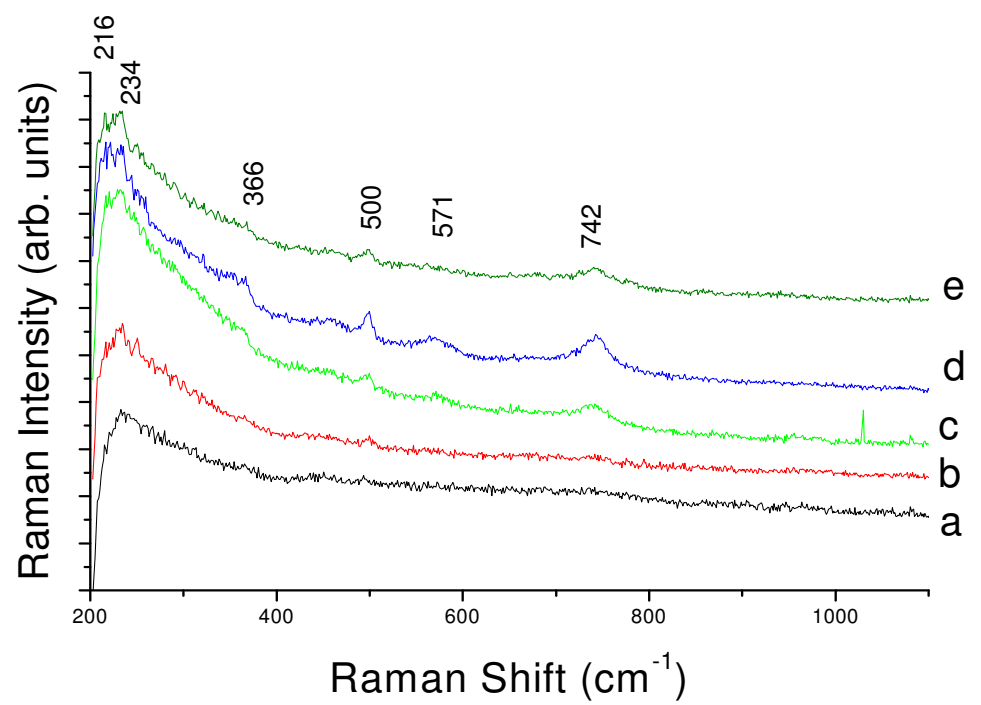

Fig. 10. Raman spectra of molybdenum irradiated with: a) 2000, b) 4000, c) 6000, d) 8000, e) 10000 ps laser pulses.

The micro-Raman spectra for the molybdenum thin film irradiated with ps are showed in Figure 10. As before, the micro-Raman spectra are displayed in the range 200 to $1000 \mathrm{~cm}^{-1}$. Five zones of the thin film were irradiated with 2000, 4000, 6000, 8000 and 10000 ps laser pulses. Each spectrum in Figure 10 corresponds to each irradiated zone.

\section{Discussion}

\subsection{LIPSS formation}

The LIPSS phenomenon has been well studied in bulk metals for laser fluences above ablation threshold, but there are no reports of this effect on metallic thin films when irradiated at laser fluences well below ablation threshold. On top of that, there are no reports at all of such LIPSS formed during the laser-induced growth of metallic oxides. In the present work, we have shown different features that can be achieved on the LIPSS formation depending on pulse duration. We selected two metals as titanium an molybdenum to show some of the main characteristic transformations, that occur when those metals in their thin film form are laser irradiated with a frequency doubled Nd:YAG laser in two distinct pulse duration regimes. For the case of titanium and ns laser pulses, it was easy to obtain LIPSS formation for samples deposited on a Silicon substrate; on the contrary it was not possible to obtain LIPSS formation when the titanium is deposited on a glass substrate, although we did get laser-induced oxidation. We did not try molybdenum deposited on Silicon. As for molybdenum deposited on glass it was neither possible to form LIPSS under ns laser irradiation, but laser-induced oxidation is still possible. Remarkably, the situation changes significantly when the titanium and molybdenum thin films deposited on glass substrates are laser irradiated with a frequency doubled Nd:YAG ps laser. For both cases, we obtained LIPSS formation with very distinct features; while titanium forms 
compact and dense LIPSS with periodicity in the order of the wavelength, molybdenum forms LIPSS covered by cone shaped structures of a few hundred nanometers size. The periodicity of the LIPSS in the case of molybdenum is twice the laser wavelength, which is somehow unexpected.

\subsection{Pulsed laser-induced oxidation}

\subsubsection{Titanium oxide induced by pulsed laser irradiation}

From the literature it is well known that the Raman spectrum for the titanium rutile phase, in the range 200 to $800 \mathrm{~cm}^{-1}$, is constituted by three bands located at 236, 444, $609 \mathrm{~cm}^{-1}$ (Porto et al., 1967; Beattie I. R., Gilson T. R. 1967; Escobar-Alarcón et al., 1999). There is good agreement between the Raman peak positions obtained for de irradiated zones with ns and ps pulses (Figures 7 and 8) and those reported in the literature for the rutile phase. This indicates that the irradiated material suffered an oxidation passing from $\mathrm{Ti}$ to $\mathrm{TiO}_{2}$ in its rutile phase. This transformation was obtained by (Pérez del Pino et al., 2002) irradiating titanium targets by using the fundamental line $(1064 \mathrm{~nm})$ of a Nd:YAG laser. Additionally to the rutile phase, they found another phases like $\beta-\mathrm{Ti}_{2} \mathrm{O}_{3}$ and $\mathrm{TiO}$ into the irradiated zones. Analyzing our spectra for the ns pulses, we can observe two bands at 445 and $335 \mathrm{~cm}^{-1}$ that could be assigned to $\mathrm{Ti}_{2} \mathrm{O}_{3}$. Therefore, the Raman results indicate that a mixture of $\mathrm{TiO}_{2}$ and $\mathrm{Ti}_{2} \mathrm{O}_{3}$ is present in the irradiated zones. It is worth noting that in the case of ps pulses, the Raman spectra do not present the bands corresponding to the $\mathrm{Ti}_{2} \mathrm{O}_{3}$ phase. In this case only the rutile phase of $\mathrm{TiO}_{2}$ is obtained in the irradiated zones.

\subsubsection{Molybdenum oxide induced by pulsed laser irradiation}

From the literature, only a little amount of work on the Raman features for the $\mathrm{m}-\mathrm{MoO}_{2}$ can be found. For instance (R. Srivastava, R. \& Chase L. L. 1972) reported the Raman spectrum for a single crystal of $\mathrm{MoO}_{2}$. (Spevack, P. A.; McIntyre, N. S. 1992, 1993) published the Raman spectrum of $\mathrm{MoO}_{2}$ for a powder and for thin films too. (M. Dieterle, 2001) reported some molybdenum oxide Raman spectra, in particular for $\mathrm{MoO}_{2}$. (A. Blume 2004) has extensively studied the Raman spectra of a variety of $\mathrm{MoO}_{\mathrm{x}}(2 \leq \mathrm{x} \leq 3)$. Recently, (CamachoLópez et al., 2011) studied the transformation of $\mathrm{m}-\mathrm{MoO}_{2}$ to $\mathrm{MoO}_{3}$ by micro-Raman spectroscopy. The following Table presents the Raman frequencies obtained for the $\mathrm{m}-\mathrm{MoO}_{2}$ phase by several research groups. Analyzing the Raman frequencies from the literature (Table 5), some differences are observed. More detailed Raman studies on $\mathrm{MoO}_{2}$ are necessary to determine the spectral changes related to substoichiometry.

Table 6 presents the Raman frequencies obtained for the molybdenum thin films irradiated with ns and ps pulses. Comparing the frequencies obtained in the spectra 9(b-d) and 10(c-e) with those reported in the literature for the $\mathrm{m}-\mathrm{MoO}_{2}$ phase, we can point out that the position of the majority of the Raman peaks (for instance spectrum 9e) have a reasonable agreement with the characteristic Raman spectrum for the $\mathrm{m}-\mathrm{MoO}_{2}$ phase. However, the peaks of the spectra $9(\mathrm{~b}-\mathrm{d})$ and $10(\mathrm{c}-\mathrm{e})$ are wider than those for the spectrum $9(\mathrm{a})$. In particular, the FWHM for the peak $\left(744 \mathrm{~cm}^{-1}\right)$ was indicated in Table 6 . This result indicates that the crystallinity of the material in the irradiated zone is not optimized for a laser fluence of $0.08 \mathrm{~J} / \mathrm{cm}^{2}$. When the laser fluence is increased $\left(0.16 \mathrm{~J} / \mathrm{cm}^{2}\right)$, the peak position shifts towards higher frequencies and the FWHM decreases as it is observed in the spectrum 9(e). As a reference value, the FWHM of the peak centered at $744 \mathrm{~cm}^{-1}$, for a crystalline $\mathrm{MoO}_{2}$ 
powder (Table 6) and the 1D nanorods (Latha, K. et al. 2007) is $20 \mathrm{~cm}^{-1}$. For a laser fluence of $0.08 \mathrm{~J} / \mathrm{cm}^{2}$ the FWHM is $150 \mathrm{~cm}^{-1}$, while for $0.16 \mathrm{~J} / \mathrm{cm}^{2}$ the FWHM is $50 \mathrm{~cm}^{-1}$. This indicates that crystallinity can be improved with the increase in the laser fluence. The shift in the position of the Raman peaks could be related to substoichiometric molybdenum oxide induced in the irradiated zone of the thin film. It must be noted that 6000 pulses are sufficient in the two cases (ns and ps) to induce the molybdenum oxide. Optically, the molybdenum thin film did not suffered any changes.

\begin{tabular}{|c|c|c|c|c|}
\hline \multirow[t]{10}{*}{$\begin{array}{l}\text { Single crystal } \\
\mathrm{MoO}_{2} \\
(\mathrm{R} . \text { Srivastava et } \\
\text { al. 1972) }\end{array}$} & $\begin{array}{l}\text { m-MoO} 2 \\
\text { (Spevack, P. A. } \\
\text { \&McIntyre, N. S. } \\
\text { 1992) }\end{array}$ & $\begin{array}{l}\text { Powder } \\
\mathrm{m}^{-\mathrm{MoO}_{2}} \\
\text { (Camacho-lópez, } \\
\text { M. A. et al. 2011) }\end{array}$ & $\begin{array}{l}\text { m-MoO} \\
\text { (Blume, A. } \\
2004 \text { ) }\end{array}$ & $\begin{array}{l}\text { Commercial } \\
\text { Powder } \mathrm{MoO}_{2} \\
\text { (Latha, K. et al. 2007) }\end{array}$ \\
\hline & 203 & 203 & & 229 \\
\hline & & 208 & 208 & \\
\hline & 228 & 229 & 232 & 226.3 \\
\hline & 345 & 346 & & 346.2 \\
\hline & & 350 & 353 & \\
\hline & 363 & 365 & 370 & 360.2 \\
\hline & & & 448 & \\
\hline & 461 & 459 & 463 & 458.2 \\
\hline & & 469 & 473 & \\
\hline \multirow[t]{2}{*}{505} & 495 & 496 & 501 & 494.1 \\
\hline & 571 & 569 & 572 & 567.2 \\
\hline 595 & 589 & 588 & 590 & 584.4 \\
\hline 760 & 744 & 744 & 748 & 738.5 \\
\hline
\end{tabular}

Table 5. Raman frequencies for $\mathrm{m}-\mathrm{MoO}_{2}$ reported in the literature.

\begin{tabular}{llll}
\hline $\begin{array}{l}\mathrm{m}-\mathrm{MoO}_{2} \\
(\text { spectrum 9a) }\end{array}$ & $\begin{array}{l}\text { Our work } \\
\text { Nanosecond pulses } \\
\text { Spectrum 9e }\end{array}$ & $\begin{array}{l}\text { Our work } \\
\text { Nanosecond pulses } \\
\text { Spectra 9(b-d) }\end{array}$ & $\begin{array}{l}\text { Our work } \\
\text { Picosecond pulses } \\
\text { Spectra 10 (c-e) }\end{array}$ \\
\hline 203 & 211 & 218 & 216 \\
208 & 232 & 228 & 234 \\
\hline 229 & 251 & 248 & \\
\hline 346 & 349 & & 366 \\
350 & & & \\
\hline 365 & 362 & 457 & 500 \\
\hline 459 & 461 & 495 & 571 \\
\hline 469 & 496 & 565 & 742 \\
\hline 596 & 570 & & \\
\hline 589 & & $737\left(150 \mathrm{~cm}^{-1}\right)$ & \\
\hline $744\left(20 \mathrm{~cm}^{-1}\right)$ & $742\left(50 \mathrm{~cm}^{-1}\right)$ & 778 & \\
\hline
\end{tabular}

Table 6. Raman frequencies obtained in our work 


\section{Conclusions}

We have demonstrated that it is possible to create laser-induced periodic surface structures (LIPSS) on metallic (titanium and molybdenum) thin films, by irradiating the thin film with either a nanosecond or a picosecond, frequency doubled, Nd:YAG pulsed laser. We found that in the nanosecond regime the LIPSS formation seems to be influenced by the substrate type (silicon or glass); although the delivered laser fluence could also be a factor. A very interesting fact is that in the case of the irradiation with nanosecond laser pulses on titanium / silicon, the LIPSS orientation forms parallel to the laser beam polarization; while in the case of the irradiation with picosecond laser pulses on titanium / glass, the LIPSS orientation switches to perpendicular to the laser beam polarization. The last also holds for the irradiation with picosecond laser pulses on molybdenum / glass. We also demonstrated that it is feasible to obtain $\mathrm{TiO}_{2}$ in its rutile phase and $\mathrm{MoO}_{2}$ in its monoclinic phase, by using low repetition rate $\mathrm{Nd}$ :YAG pulsed lasers in the short pulse regime (nanoseconds) and the ultrashort pulse regime (picoseconds). The laser-induced metallic oxides $\mathrm{TiO}_{2}$ and $\mathrm{MoO}_{2}$ synthesize in very specific crystalline phases which depend on the laser irradiation parameters.

\section{Acknowledgements}

The authors acknowledge partial support to this work from AFOSR-CONACyT Grant FA9550-10-1-0212. We are grateful to Dr. Ivan Garcia for his support on the characterization work.

\section{References}

Aygun, G.; Atanassova, E.; Kostov K.; Turan, R. (2006). XPS study of pulsed Nd:YAG laser oxidized Si, Journal of Non-Crystalline Solids, Vol. 352 (August 2006) pp. 31343139, ISSN 0022-3093.

Beattie, I. R., Gilson, T. R. (1969) Oxide phonon spectra, J. Chem. Soc. A: Inorg. Phys. Theor. (1969) pp. 2322-2327.

Blume, A. Synthese und strukturelle Untersuchungen von Molybdän-, Vanadium- und Wolframoxiden als Referenzverbindungen für die heterogene Katalyse. PhD Tesis, Technischen Universität Berlin (2004).

Camacho-López, S.; Evans, R.; Escobar-Alarcón, L.; Camacho-López, M. A.; CamachoLópez, M. A. (2008). Polarization-dependent single-beam laser-induced grating-like effects on titanium films. Appl. Surf. Sci., Vol. 255 (December 2008), pp. 3028, ISSN 01694332.

Camacho-López, M. A.; Escobar-Alarcón, L.; Picquart, M.; Arroyo, R.; Córdoba, G.; HaroPoniatowski, E. (2011). Micro-Raman study of the $m-\mathrm{MoO}_{2}$ to a-MoO $\mathrm{O}_{3}$ transformation induced by cw-laser irradiation. Opt. Mater., Vol. 33 (January 2011) 480, ISSN 09253467.

Cano-Lara, M.; Camacho-López, S.; Esparza-García, A.; Camacho-López, M. A. (2011). Laserinduced molybdenum oxide formation by low energy ( $\mathrm{nJ})$-high repetition rate $(\mathrm{MHz})$ femtosecond pulses. Optical Materials, Vol. 33 (September 2011) pp. 1648-1653, ISSN 0925-3467. 
Dieterle, M. In situ resonance Raman studies of molybdenum oxide based selective oxidation catalysts. PhD Tesis, Technische Universität Berlin (2001).

Dong, Q.; Hu, J.; Lian, J.; Guo, Z.; Chen, J.; Chen B. (2003). Oxidation behavior of Cr films by Nd:YAG pulsed laser. Scripta Materialia, Vol. 48 (May 2003) pp. 1373-1377, ISSN 1359-6462.

Dubey, A. K.; Yadava, V. (2008) Experimental study of Nd:YAG laser beam machining - An overview. Journal of materials processing technology. Vol. 195 ( January 2008 ), 15-26. ISSN 0924-0136.

Escobar-Alarcón, L.; Haro-Poniatowski, E.; Camacho-López, M. A.; Fernández-Guasti, M.; Jímenez-Jarquín, J.; Sánchez-Pineda, A. (1999) Structural characterization of $\mathrm{TiO}_{2}$ thin films obtained by pulsed laser deposition, Applied Surface Science Vol. 137 (January 1999) pp. 38-44. ISSN 0169-4332.

Evans, R.; Camacho-Lopez, S.; Camacho-Lopez, M. A.; Sanchez-Perez, C.; Esparza-Garcia, A. (2007). Pulsed laser-induced effects in the material properties of tugnsten thin films. J. of Phys. CS., Vol. 59, pp. 436-439, ISSN 1742-6596.

Hermann, J.; Benfarah, M.; Coustillier, G.; Bruneau, S.; Axente, E.; Guillemoles, J. F.; Sentis, M. Alloncle, P.; Itina, T. (2006). Selective ablation of thin films with short and ultrashort laser pulses. Applied Surface Science. Vol. 252, (April 2006), pp. 4814-4818. ISSN 0169-4332.

Jun, Z.; Ning-Sheng, X.; Shao-Zhi D., Jun, C.; Jun-Cong S.; Zhong-Ling W. (2003). Large-Area Nanowire Arrays of Molybdenum and Molybdenum Oxides: Synthesis and field emission properties. Adv. Mater. Vol. 15 (November 2003), pp. 1835-1840.

Latha, K.; Yuan-Ron M.; Chai-Chang T.; Yi-Way L.; Sheng Yun W.; Kai-wen C.; Yung L. (2007) X-ray difracction and Raman scattering studies on large-area array and nanobranched structure of $1 \mathrm{D} \mathrm{MoO}_{2}$ nanorods, Nanotechnology Vol. 18 (March 2007) pp. 1-6. ISSN 0957-4484.

Lavisse, L.; Grevey, D.; Langlade, C.; Vannes, B. (2002). The early stage of the laser-induced oxidation of titanium substrates. Applied Surface Science, Vol. 186 (January 2002), pp. 150-155, ISSN 0169-4332.

Linsebigler A. M., Lu G. , Yates J. T., Jr.(1995). Photocatalysis on $\mathrm{TiO}_{2}$ Surfaces: Principles, Mechanisms, and Selected Results. Chem. Rev. Vol. 95 (July 1995) pp. 735-758.

Livage, J., Ganguli, D. (2001). Sol gel electrochromic coatings and devices: A review. Solar Energy Materials \& Solar Cells Vol. 68 ( June 2001) pp. 365-381 ISSN 0927-0248.

Maisterrena-Epstein, R.; Camacho-Lopez, S.; Escobar-Alarcon, L,; Camacho-Lopez, M. A. (2007). Nanosecond laser ablation of bulk Al, Bronze, Cu: ablation rate saturation and laser-induced oxidation. Superficies y Vacio, Vol. 20 (September 2007), pp. 1-5, ISSN 1665-3521.

Mikhailova, D.; Bramnik, N. N.; Bramnik, K. G.; Reichel, P.; Oswald, S.; Senyshyn A.; D. M. Trots.; H. Ehrenberg. (2011). Layered LixMoO 2 Phases with Different Composition for Electrochemical Application: Structural Considerations, Chem. Mater. (July 2011), Vol. 23, pp. 3429-3441.

Pereira, A.; Delaporte, P.; Sentis, M.; Cros, A.; Marine W.; Basillais, A.; Thomann, A. L.; Leborgne, C.; Semmar, N. Andreazza P.; Sauvage T. (2004). Laser treatment of a steel surface in ambient air. Thin Solid Films Vols 453-454, (April 2004), pp. 16-21. ISSN 0040-6090. 
Pérez del Pino, A.; Serra, P.; Morenza, J. L. (2002). Oxidation of titanium through Nd:YAG laser irradiation. Applied Surface Science, Vol. 197-198 (September 2002), pp. 887-890, ISSN 0169-4332.

Porto, S. P. S.; Fleury, P. A.; Damen, T.C. (1967) Raman Spectra of $\mathrm{TiO}_{2}, \mathrm{MgF}_{2}, \mathrm{ZnF}_{2}, \mathrm{FeF}_{2}$, and $M n F_{2}$, Phys. Rev. Vol. 154 (February 1967) pp. 522-526.

Sipe, J. E.; Young, J. F.; Preston, J. S.; Van Driel H. M. (1983). Laser-induced periodic surface structure. I. Theory. Phys. Rev. B Vol. 27 (January 1983), pp. 1141-1154. ISSN 10980121.

Spevack, P.A.; McIntyre, N. S. (1992). Thermal reduction of molybdenum trioxide. J. Phys. Chem., Vol. 96 (October 1992) pp. 9029-9035. ISSN 0022-3654.

Spevack, P. A.; McIntyre, N. S. (1993). A Raman and XPS investigation of supported molybdenum oxide thin films. 1. Calcination and reduction studies. J. Phys. Chem., (October 1993), 97 (42), pp 11020-11030. ISSN: 0022-3654.

Srivastava R.; Chase L. L. (1972) Raman spectra of $\mathrm{CrO}_{2}$ and $\mathrm{MoO}_{2}$ single Crystals, Solid State Communications Vol. 11 (July 1972) pp. 349-353. ISSN 0038-1098.

Vorobyev, A. Y.; C. Guo, C. (2007). Residual thermal effects in laser ablation of metals J. Phys. CS Vol. 59 (2007) 418-423.

Young, J. F.; Preston, J. S.; van Driel, H. M.; Sipe, J. E. (1983). Laser-induced periodic surface structure. II. Experiments on Ge, Si, Al, and brass. Phys. Rev. B 27 (January 1983), pp. 1155-1172. ISSN 1098-0121.

Wang F.; Lu B. (2009). Well-aligned $\mathrm{MoO}_{2}$ nanowiresarrays: Synthesis and field emission properties. Physica B Vol. 404 (December 2009) 1901-1904. ISSN 0921-4526.

Witke, K.; Klaffke, D.; Skopp, A.; Schreckenbach, J. P. (1998). Laser-induced transformation as a tool for structural characterization of materials by Raman spectroscopy. J. Raman Spectrosc., Vol 29 (May 1998) pp. 411-415. ISSN 0169-4332. 


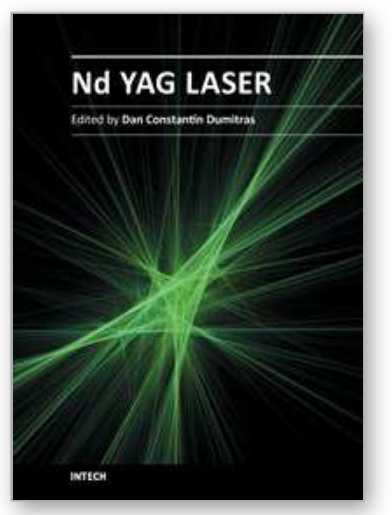

\author{
Nd YAG Laser \\ Edited by Dr. Dan C. Dumitras
}

ISBN 978-953-51-0105-5

Hard cover, 318 pages

Publisher InTech

Published online 09, March, 2012

Published in print edition March, 2012

Discovered almost fifty years ago at Bell Labs (1964), the Nd:YAG laser has undergone an enormous evolution in the years, being now widely used in both basic research and technological applications. Nd:YAG Laser covers a wide range of topics, from new systems (diode pumping, short pulse generation) and components (a new semiorganic nonlinear crystal) to applications in material processing (coating, welding, polishing, drilling, processing of metallic thin films), medicine (treatment, drug administration) and other various fields (semiconductor nanotechnology, plasma spectroscopy, laser induced breakdown spectroscopy).

\title{
How to reference
}

In order to correctly reference this scholarly work, feel free to copy and paste the following:

Santiago Camacho-López, Marco A. Camacho-López, Oscar Olea Mejía, Rodger Evans, Gabriel Castillo Vega, Miguel A. Camacho-López, Manuel Herrera Zaldivar, Alejandro Esparza García and José G. Bañuelos Muñetón (2012). Processing of Metallic Thin Films Using Nd:YAG Laser Pulses, Nd YAG Laser, Dr. Dan C. Dumitras (Ed.), ISBN: 978-953-51-0105-5, InTech, Available from: http://www.intechopen.com/books/nd-yaglaser/processing-of-metallic-thin-films-using-nd-yag-laser-pulses

\section{INTECH}

open science | open minds

\section{InTech Europe}

University Campus STeP Ri Slavka Krautzeka 83/A 51000 Rijeka, Croatia Phone: +385 (51) 770447 Fax: +385 (51) 686166 www.intechopen.com

\section{InTech China}

Unit 405, Office Block, Hotel Equatorial Shanghai No.65, Yan An Road (West), Shanghai, 200040, China 中国上海市延安西路65号上海国际贵都大饭店办公楼 405 单元 Phone: $+86-21-62489820$

Fax: $+86-21-62489821$ 
(C) 2012 The Author(s). Licensee IntechOpen. This is an open access article distributed under the terms of the Creative Commons Attribution 3.0 License, which permits unrestricted use, distribution, and reproduction in any medium, provided the original work is properly cited. 